\title{
INFLUENCIA DO MESOCARPO DE COCO BABAÇU NA FORMAÇÃO DE BIOFILMES ADITIVADOS COM COMPOSTOS ANTIOXIDANTES - CUPUAÇU (Theobroma grandiflorum).
}

\author{
M. F. LIMA ${ }^{1}$, D. C. SILVA $^{1}$, H. A. V. VELLEZ ${ }^{1}$, A. A. SANTANA ${ }^{1}$ \\ ${ }^{1}$ Universidade Federal do Maranhão, Centro de Ciências Exatas e suas Tecnologias, \\ Departamento de Engenharia Química \\ E-mail para contato: meyrellefigueiredo@ hotmail.com
}

\begin{abstract}
RESUMO - Filmes biodegradáveis são produzidos a partir de polímeros naturais, principalmente polissacarídeos e proteínas com potencial aplicação na indústria farmacêutica e alimentícia. A incorporação do mesocarpo de coco babaçu além de conferir maior resistência ao filme, proporciona melhores propriedades físicoquímicas. O objetivo deste trabalho é avaliar o comportamento do mesocarpo de coco babaçu e da incorporação de extratos de frutas, no caso o cupuaçu, a fim de lhes conferir atividade antioxidante durante o processo de confecção de filmes de carboidratos e proteínas, assim como caracterizar as interações sinérgicas entre os plastificantes orgânicos, a estrutura reticulada dos carboidratos e proteínas e o poder plastificante da água e seus reflexos sobre as propriedades físicas de interesse para embalagens de alimentos e fármacos. O cupuaçu foi aliado a uma matriz de melhor rigidez, pois possui um alto teor de água, sendo necessária a utilização de uma matriz mais resistente. Os biofilmes apresentaram boa visibilidade, flexibilidade e facilidade de desprendimento do suporte. Altas concentrações de alginato de sódio, mesocarpo de coco babaçu e glicerol seriam ideais para uma futura produção de sacolas.
\end{abstract}

\section{INTRODUÇÃO}

O babaçu (Orbignya phalerata Mart.) é uma das mais importantes representantes das palmeiras brasileiras. Esta palmeira é nativa das regiões norte, nordeste e centro-oeste do Brasil. O Nordeste brasileiro possui uma área de cerca de 18 milhões de hectares plantados com babaçu, sendo que a maior parte está concentrada no estado do Maranhão. Ele tem 64 usos catalogados, dos quais cerca de uma dezena poderia ser economicamente viável; contudo, seu potencial continua inexplorado, devido à falta de escala e estrutura produtiva (Carraza et al., 2012).

O Cupuaçu pertence à família Sterculiacea de denominação Theobroma grandiflorum schum. É uma fruta típica da Amazônia, mas também cultivada nos estados do Pará, Maranhão e Tocantins. Sua polpa possui um forte aroma e um notável sabor ácido, sendo empregada em doces no geral e possui maior comercialização quando congelada. Há diversos 
estudos científicos, tanto no Brasil quanto no exterior, que utilizam as sementes do cupuaçu e sua polpa para tratar doenças no trato gastrointestinal. Essas pesquisas apontam também o uso do cupuaçu como antioxidante e como base para desenvolvimento de produtos de beleza.

Pesquisas focadas no desenvolvimento de películas comestíveis/biodegradáveis baseada em polissacáridos e proteínas como matrizes para ser utilizado como proteção de alimento e fármacos têm aumentado nos últimos anos. Filmes e recobrimentos comestíveis/ biodegradáveis são aqueles formados a partir de polímeros naturais, de origem animal ou vegetal, como polissacarídeos, lipídios e proteínas e que quando lançados no meio ambiente, convertem-se em compostos simples, mineralizados, que, redistribuídos através dos ciclos de carbono, nitrogênio e enxofre não agridem o biossistema.

Os filmes biodegradáveis são preparados geralmente pelo método casting pelo qual a solução aquosa é depositada numa superfície apropriada e secada posteriormente. A formação do filme envolve ligações inter e intramoleculares ou a reticulação das cadeias dos polímeros, formando assim uma rede tridimensional semi-rígida que retém e imobiliza o solvente. O grau de coesão depende da estrutura do polímero, do solvente usado, da temperatura e a presença de outras moléculas, como os plastificantes (Jiménez, 2007). A escolha do plastificante a ser adicionado aos filmes depende da compatibilidade deste com o polímero e o solvente utilizados, isto é, deve ser miscível no polímero e no solvente, de forma a evitar a separação prematura no decorrer do processo de secagem. A concentração de plastificante usado na elaboração de filmes geralmente varia de 10 a $60 \mathrm{~g} / 100 \mathrm{~g}$ de matéria seca de polímero, dependendo da flexibilidade desejável no filme (Guilbert et al., 1996).

Uma das tecnologias mais promissoras da área de embalagens e conservação de alimentos é a utilização de filmes e coberturas comestíveis formadas por polímeros incorporados de compostos naturais, que além de manter a qualidade e a segurança dos alimentos, conferem ao produto extensão da vida útil e proteção à inibição dos efeitos de oxidação do mesmo.

Este trabalho teve por finalidade avaliar o comportamento do mesocarpo de coco babaçu e da incorporação de extratos de frutas, caracterizar as interações sinérgicas entre os plastificantes orgânicos, a estrutura reticulada dos carboidratos e proteínas e o poder plastificante da água e seus reflexos sobre as propriedades físicas de interesse para embalagens de alimentos e fármacos.

\section{MATERIAIS E MÉTODOS}

\subsection{Matérias-Primas}

Para a confecção dos filmes foi utilizado coco babaçu disponível na flora da Universidade Federal do Maranhão (UFMA), cloreto de cálcio dihidratado (Merck Alemanha), glicerol (Dinâmica Química Contemporânea LTDA) e alginato de sódio puríssimo (Isofar).

\subsection{Elaboração Dos Filmes}


Os cocos babaçu foram lavados em água corrente para retirar as sujidades grosseiras (como areia, palha e materiais indesejáveis). Em seguida, foram retirados os mesocarpos e secados em estufa à vácuo a $105^{\circ} \mathrm{C}$ até obtenção de umidade menores que $3 \%$, que são propícias a produtos em pó. Depois, foram triturados em moinhos de martelo, bola e faca e peneirados.

Os filmes foram confeccionados de acordo com metodologia estabelecida por Silva et al. (2016) e Santana et al. (2013), sendo obtidos segundo a técnica de casting, a qual consiste na preparação da solução filmogênica e aplicação conveniente da mesma em um suporte (placas de estireno, $\mathrm{d}=14 \mathrm{~cm}$ ). A espessura dos filmes foi controlada através da massa de solutos na solução filmogênica vertida no suporte (aproximadamente $50 \mathrm{ml}$ ). A secagem dos filmes foi a $40^{\circ} \mathrm{C}$ em estufa com recirculação de ar (Nova Ética, $4001 \mathrm{ND}$, Brasil) durante 1820 horas. Após a secagem, os filmes foram removidos do suporte e armazenados a uma umidade relativa de $52 \%$.

\subsection{Caracterização dos Filmes}

Os filmes foram caracterizados quanto ao conteúdo de umidade $(\omega)$, solubilidade em água (S), espessura ( $\delta)$, gramatura $(\mathrm{G})$ e sua cinética de secagem.

Conteúdo de umidade c: determinado por gravimetria usando estufa à vácuo a $105^{\circ} \mathrm{C}$ durante 24 h. O cálculo da umidade é expresso em fração de massa conforme a Equação 1:

$$
\omega=\left(m_{i}-m_{f} / m_{i}\right) \times 100
$$

onde $\omega$ é a porcentagem de umidade; $m_{i}$ é a massa inicial do material e $m_{f}$ é a massa final do material seco.

Solubilidade em água $(\mathrm{S})$ : A massa $\left(m_{i}\right)$ de uma amostra dos filmes é quantificada e imersa em $50 \mathrm{ml}$ de água destilada sob agitação $(175 \mathrm{rpm})$ à $25^{\circ} \mathrm{C}$ por $24 \mathrm{~h}$, utilizando-se uma mesa agitadora orbital (Tecnal, modelo TE-145, Brasil). Após esse tratamento, as soluções com as amostras são levadas à estufa para a determinação da massa seca final, $m_{f}$. A porcentagem de solubilidade foi calculada segundo Gontard através da Equação 2.

$$
\% S=\left(m_{i}-m_{f} / m_{i}\right) \times 100
$$

Espessura $(\delta)$ : medida com micrômetro digital com resolução 0,001 mm (Mitutoyo, modelo MDC-25S, Japão).

Gramatura (G): foi determinada segundo SOBRAL (1999) pela pesagem de uma área definida do filme em balança analítica utilizando-se a Equação 3.

$$
G=100000 \times \frac{P}{A}
$$

Cinética de Secagem: Pedaços de filme contendo a solução polimérica foram pesados em intervalos de tempo predefinidos durante o processo de secagem (controle gravimétrico), a 
fim de avaliar a secagem cinética para cada condição. Os pedaços foram secos até atingir peso constante (estado de equilíbrio), observando-se diferentes tempos de secagem. O teor de umidade final dos filmes foi determinado no final do processo de secagem.

Silva et al. (2016a) concluiu através de seus ensaios que os biofilmes preparados pela mistura de pectina e MCB apresentaram propriedades melhoradas quando comparadas aos filmes preparados a partir de pectina pura, apresentando variabilidade na aparência e facilidade de remoção dos moldes. A resposta obtida através de um Delineamento Composto Central Rotacional (DCCR) para permeabilidade de água não foi influenciada ao nível de $10 \%$ de significância pelas variáveis independentes (alginato de sódio, mesocarpo de coco babaçu e glicerol) estudadas. Já as respostas umidade, solubilidade e espessura apresentam $\mathrm{R}^{2}$ de $75 \%, 64 \%$ e $88 \%$, respectivamente.

Para a produção futura de sacolas então, o ideal seria a utilização de altas concentrações de pectina, MCB e glicerol. Foram utilizadas então nesse trabalho formulações chamadas de formulações ótimas, substituindo a pectina pelo alginato. A Formulação 1 possui maior quantidade de glicerol $(5 \mathrm{ml})$ enquanto a Formulação 2 possui menor $(1 \mathrm{ml})$, além da adição da polpa do cupuaçu em conjunto com a água destilada. O cupuaçu possui a função de antioxidante, fator proposto por Silva et al. (2016b). Após a confecção das duas formulações, testes de umidade, solubilidade, espessura e cinética de secagem foram realizados.

\section{RESULTADOS E DISCUSSÕES}

Os valores obtidos para o conteúdo de umidade $(\omega)$ e solubilidade em água (S) dos filmes são mostrados nas Tabelas 1 e 2 , respectivamente.

Tabela 1: Conteúdo de umidade dos filmes contendo mesocarpo de coco babaçu

\begin{tabular}{|c|c|c|}
\hline Ensaios & Média Umidade & $\omega(\%)$ \\
\hline 1 & 0,15 & $15,48 \pm 0,01$ \\
\hline 2 & 0,28 & $28,11 \pm 0,01$ \\
\hline
\end{tabular}

Média em triplicata \pm desvio padrão.

Os filmes da Formulação 2, obtiveram maior resultado para umidade $(\omega)$ e solubilidade (S) do que a Formulação 1 devido a menor quantidade de plastificante existente o que permite um maior preenchimento de umidade e melhor solubilidade do filme, possibilitando a quebra das moléculas do polímero.

Tabela 2: Conteúdo de solubilidade (S) dos filmes contendo mesocarpo de coco babaçu

\begin{tabular}{|c|c|c|}
\hline Ensaios & Média Solubilidade & S (\%) \\
\hline 1 & 49,67 & $49,67 \pm 2,43$ \\
\hline 2 & 69,34 & $69,34 \pm 6,03$ \\
\hline
\end{tabular}

Média em triplicata \pm desvio padrão. 
Já de acordo com as Tabelas 3 e 4, a gramatura dos filmes foram iguais e a Formulação 1 apresentou maior espessura, respectivamente, em relação a Formulação 2, resultado explicado pela presença do antioxidante de cupuaçu nos filmes, o que causa maior rigidez nas suas ligações.

Tabela 3: Gramatura dos filmes contendo mesocarpo de coco babaçu

\begin{tabular}{|c|c|c|}
\hline Ensaio & Gramatura da Solução $\left(\mathrm{g} / \mathrm{cm}^{2}\right)$ & Gramatura do Filme $\left(\mathrm{g} / \mathrm{cm}^{2}\right)$ \\
\hline 1 & $3249,39 \pm 0,56$ & $260,72 \pm 0,81$ \\
\hline 2 & $3249,42 \pm 0,68$ & $260,72 \pm 0,81$ \\
\hline
\end{tabular}

Média em triplicata \pm desvio padrão.

Tabela 4: Espessura dos filmes contendo mesocarpo de coco babaçu

\begin{tabular}{|c|c|}
\hline Ensaio & Média geral - Espessura Inicial $(\mathrm{mm})$ \\
\hline 1 & $0,37 \pm 0,11$ \\
\hline 2 & $0,33 \pm 0,04$ \\
\hline
\end{tabular}

Devido ao alto teor de água presente na polpa do cupuaçu, a cinética de secagem dos filmes foi realizada a uma temperatura de $80^{\circ} \mathrm{C}$. Na Figura 1, observa-se os gráficos das variações das razões de umidade para os filmes de Formulação 1 e 2.

Figura 1: Variação da razão de umidade em função do tempo.

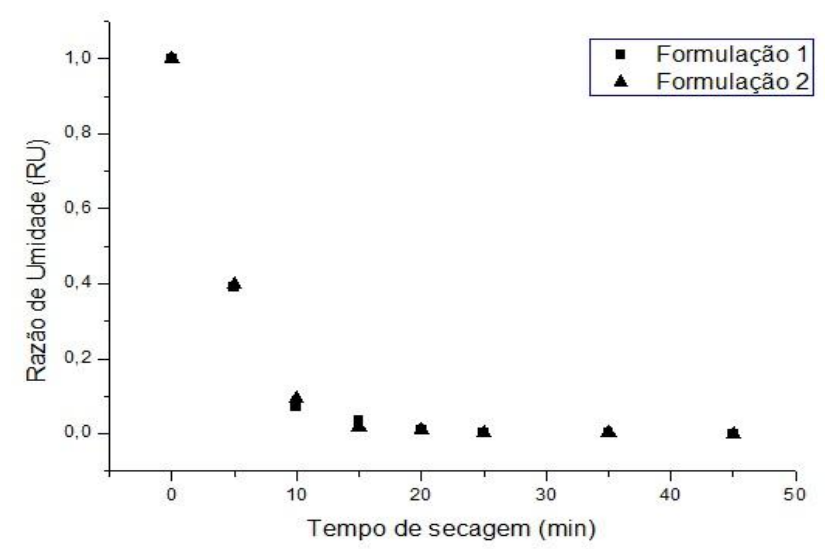

É observada na Figura 1 a influência do ar na cinética do processo sendo previsto que quanto maior for a temperatura, menos tempo levará para a amostra estabilizar. As duas formulações possuem aproximadamente o mesmo comportamento da curva, porém a Formulação 2 apresenta um maior teor de secagem ocasionado por ter uma menor quantidade de glicerol, o que ocasiona um maior preenchimento de água no meio poroso. 


\section{CONCLUSÃO}

Os biofilmes apresentaram boa visibilidade, flexibilidade e fácil de manusear (facilidade de desprendimento do suporte). A polpa do cupuaçu possui um alto teor de água, por isso foi necessário alia-lo a uma matriz de melhor rigidez, como o mesocarpo do coco babaçu, para a confecção dos filmes biodegradáveis. Para uma futura produção de sacolas, mostrou-se ideal utilizar altas concentrações de alginato de sódio, mesocarpo de coco babaçu e glicerol.

\section{REFERÊNCIAS}

CARraZA, L. R.; SILVA, M. L. D. A.; ÁVILA, J. C. C. Manual tecnológico de aproveitamento integral do fruto do babaçu. Brasília: Instituto Sociedade, População e Natureza (ISPN), 2012.

GONTARD, N. GUILBERT, S. CUQ, J. L. Edible wheat gluten film: I. Influence of the main process variables on films properties of an edible using response surface methodology. Food Sci. Technol (Campinas), v. 57, p. 190, 1992.

JIMÉNEZ, E. N. Propriedades mecânicas e de barreira, solubilidade e microestrutura de filmes de farinha de amaranto modificada com epicloridrina ou misturada com poli (vinil álcool). Faculdade de Engenharia de Alimentos, Universidade Estadual de Campinas, 2007.

SANTANA, A. A.; KIECKBUSCH, T. G. Physical evaluation of biodegradable films of calcium alginate plasticized with polyols. Braz. J. Chem. Eng., v. 30, p. 835 - 845, 2013.

SILVA, D. C., SILVA, L. J.S., SANTANA, A.A., LOPES, I.A. Filmes de pectina incorporado de mesocarpo de coco babaçu. Anal do XXI Congresso de Engenharia Química. Fortaleza, 2016a.

SILVA, D. C.; PESSOA, M. A.; LIMA, M. F.; VÉLEZ, H. A. V. SANTANA, A.A. Estudo da modelagem de cinética de secagem da polpa de cupuaçu na produção de biopolímeros. Anal do $3^{\circ}$. Encontro Nordeste de Ciência e Tecnologia de Polímeros. Fortaleza, 2016 b. 